\title{
The first symptom of hyperkalaemia is death
}

$\mathrm{T}$ he EBM note by Glasziou on hyperkalemia ${ }^{1}$ brought to mind my old bias dating back more than 50 years. A serum potassium of $7.3 \mathrm{mmol} / \mathrm{l}$ in an otherwise healthy individual does not fit the adage of a renal physician, "the first symptom of hyperkalaemia is death." I am convinced that any serious effect of hyperkalaemia must result from the concentration of intracellular potassium, which we are still unable to measure clinically. One of the mechanisms of hyperkalaemia is the release of potassium from cells,

A repeated serum potassium value of $7.3 \mathrm{mEq} / \mathrm{l}$ in the US would cause the patient to be immediately transported to an emergency room (ER) and given top priority by the ER staff and physicians. The author did not repeat the serum potassium immediately. Why? He then indirectly indicates that this patient was seen in an office, "she was booked to see me," a second serious error. Finally, death is not the first sign, symptom, or finding of hyperkalaemia.

The belated second blood test confirmed hyperkalaemia. Severe hyperkalaemia on repeated blood testing will give almost exactly the same result (the accuracy of a serum potassium can be within $0.2 \mathrm{mEq} / \mathrm{l}$ per standard deviation), factitious causes of hyperkalaemia excluded. Were they?

Another physician should be immediately sought. Did the author do this or consult a standard reference book on medicine on how to diagnose, then treat, hyperkalaemia? If the author had queried a knowledgeable nephrologist, he would have been told: (a) the most common symptom of hyperkalaemia is muscular weakness, not death; (b) we have seen extremity numbness and occasionally tingling, an irregular heartbeat perceived by the patient, and most alarming, a vague sense of doom; (c) was the body temperature less than normal? (hypothermia is common); and (d) a non-diagnostic ECG result is usual. A positive ECG result, with classically tented T-waves, is seen in those patients just about to develop ventricular failure.

\section{IN RESPONSE:}

The contradictory advice in the letters illustrates the need for checking research evidence to resolve uncertainty and disagreements about factual information. Dr Grossman believes that without a rise in intracellular potassium, a serum level of $7.3 \mathrm{mmol} / \mathrm{l}$ is "certainly not a dangerous situation," whereas Dr de Palma suggests emergency transportation despite the patient's wishes. How should I resolve such differences? For questions of fact-but not of values-I would prefer to use research evidence, but there are several notable alternatives, including eminence, vehemence, certainly not a dangerous situation. Might the $62 \%$ sensitivity reported for electrocardiographic (ECG) changes suggest that $38 \%$ had no real increase in intracellular potassium? Was Dr. Glasziou's patient wiser than the renal specialist when she refused to accept a doctor created emergency?

CHARLES M GROSSMAN, MD Portland, Oregon, USA 1 Glasziou P. Practice corner: the first symptom of hyperkalaemia is death [EBM note]. EBM 2004;9:8-9.

The comment is made that the patient had "mild renal failure." The surmise was that she had hyperkalaemia because she subsisted on a diet of "...mangos and fruit juice..." It is almost impossible to become hyperkalaemic from a fruit diet with "mild renal failure" and an adequate intake of high biologic value protein. Can we assume $(p>0.68)$ that this woman is both overweight and on some kind of fad diet? If so, then she is catabolic. If true, then her need to excrete potassium is markedly increased. If fruit is this woman's diet, then it is impossible $(p=0)$ for her to remain in protein balance.

Since the definition of "mild renal failure" depends on what country you are in, my guess is that the author meant a glomerular filtration rate (GFR) $>25 \%$. Some American investigators have set "mild renal failure" at about $80 \%$ of normal GFR. If her $100 \%$ normal renal function was a serum creatinine of $0.6 \mathrm{mg} / \mathrm{dl}(53 \mu \mathrm{mol} / \mathrm{l})$ at the age of 21 years; a serum creatinine of, say $2.5 \mathrm{mg} / \mathrm{dl}(221 \mu \mathrm{mol} / \mathrm{L})$ at age 50 is not "mild renal failure" in any country. One could use the Cockcroft/Gault ${ }^{1}$ formula to calculate an estimate of her GFR. Prayerfully, one would not use a more recent (but less sound) formula that calculates GFR per $1.73 \mathrm{~m}^{2}$ without use of the height or weight, a bizarre concept.

JOHN R DE PALMA, MD, FACP Hemodialysis, Inc Santa Monica, California, USA 1 Cockcroft DW, Gault MH. Prediction of creatinine clearance from serum creatinine. Nephron 1976;16:31-41.

eloquence, providence, diffidence, nervousness, and confidence based medicine. ${ }^{1}$

Since the letters suggest I did not clearly spell out the sequence of events, let us turn to these first. The patient was sent to our clinic immediately when hyperkalaemia was detected and hence she was on her way to our clinic before I was notified. When she arrived, I did precisely as Dr de Palma suggested and (a) repeated the potassium immediately (to exclude a factitious rise due to collection method); (b) checked vital signs; (c) arranged an ECG and kept the patient monitored; (d) noted that other than the potassium and 
creatinine changes, biochemistry was normal; (e) took a pertinent history, physical examination, and read an (unhelpful) textbook; and (f) insisted the patient go to the ER. But she (of sound mind) equally insistently refused, and physical force is not permitted in Australia-unless the patient is a danger to herself and has a mental illness (she did not).

Dr de Palma suggested I read a standard reference book to diagnose hyperkalaemia, but does not nominate a specific text. The one in my room was unhelpful, so I have since checked 2 others. Both dismiss muscle weakness as an inconsistent finding in hyperkalaemia, and recommend an ECG but do not give the accuracy to rule in (specificity) or rule out (sensitivity) hyperkalaemia. Specifically, the Oxford Textbook of Medicine ${ }^{2}$ states that "The best guide to the significance of hyperkalaemia in any particular individual is the impact on the ECG, and the ECG should be obtained immediately" as I did, and states that "patients may occasionally notice muscle weakness." Emedicine (www. emedicine.com) states that "Neurologic examination may reveal diminished deep tendon reflexes or decreased motor strength. In rare cases, muscular paralysis and hypoventilation may be observed." And although it stated that "ECG findings generally correlate with the potassium level," it also pointed out that "potentially life threatening arrhythmias can occur without warning at almost any level of hyperkalaemia," with reference to a series of 7 patients with potassium $>8.0 \mathrm{mmol} / \mathrm{l}$ and no or minimal ECG changes. ${ }^{3}$ Both texts list several treatments, first suggesting insulin and glucose but, unlike most texts, do not mention $\beta$ agonist treatment-3 decades after its first proven use for hyperkalaemia.

I gather Dr de Palma was not completely serious with all his suggestions. In particular, he suggested that a fruit diet in mild renal failure cannot lead to hyperkalaemia, but then kindly tells us how this is achievable with a low protein, low calorie diet-exactly the circumstances of my patient.

I have gleaned several insights from the letters, although I don't think this would have changed my decisions. However, as a family practitioner unable to keep up in all specialties, I do enjoy hearing from specialists. I would just ask when giving advice that they (a) listen to the problem and circumstances before giving advice, (b) aim to be helpful rather than impressive, and (c) direct me to the evidence that backs up recommendations for action.

PAUL GLASZIOU, MBBS, PhD Centre for Evidence-Based Medicine Oxford, England, UK

1 Isaacs D, Fitzgerald D. Seven alternatives to evidence based medicine. BMJ 1999;319:1618.

2 Warrell DA, Cox TM, Firth JD, et al. editors. Oxford textbook of medicine, 4th ed. Oxford: Oxford University Press, 2003.

3 Martinez-Vea A, Bardaji A, Garcia C, et al. Severe hyperkalemia with minimal electrocardiographic manifestations: a report of seven cases. $J$ Electrocardiol 1999;32:45-9.

\section{Call for papers}

10th European Forum on Quality Improvement in Health Care

13-15 April 2005, ExCel, Docklands, London

For further information on how to submit your paper please go to:

http://www.quality.bmipg.com

\section{Making Health Care Safer 2004}

21-22 October 2004

Royal College of Physicians, London

A two day conference for all professionals dedicated to providing safer health care for all.

Register now! Early booking discount available.

See website for details: www.quality.bmipg.com 